\title{
RTDF2010-420]
}

\section{COLLISION SCENARIOS FOR ASSESSING CRASHWORTHINESS OF PASSENGER RAIL EQUIPMENT}

\author{
Karina Jacobsen \\ Patricia Llana \\ David Tyrell \\ Volpe National Transportation Systems Center \\ US Department of Transportation \\ Cambridge, MA 02142
}

\section{ABSTRACT}

In June 2009, at the request of the Federal Railroad Administration (FRA), the Railroad Safety Advisory Committee established the Engineering Task Force (ETF). The ETF is comprised of government, railroads, suppliers, and labor organizations and their consultants. The ETF was tasked with recommending a process for assessing alternative Tier I passenger rail equipment, i.e., passenger equipment that is operated at speeds up to $125 \mathrm{mph}$ on the general railroad system. The final product of the ETF is a document outlining criteria and procedures for demonstrating crashworthiness performance of passenger rail equipment built to alternative design standards and proposed for operation in the US. The results provide a means of assessing whether an alternative design compares to designs compliant with the FRA's Tier I crashworthiness requirements.

This paper focuses on the criteria and procedures developed for scenario-based requirements. The principle collision scenario describes the minimum train-level crashworthiness performance required in a train-to-train collision of an alternatively designed passenger train with a conventional locomotive-led passenger train. For cab car-led and $\mathrm{MU}$ locomotive-led operations, the impact speed is prescribed at $20 \mathrm{mph}$. For locomotive led operations, the impact speed is prescribed at $25 \mathrm{mph}$. Criteria for evaluating this scenario include intrusion limits for the passengers and engineer, and occupant protection measures. Other scenariobased requirements discussed in this paper include colliding equipment override, connected equipment override, and truck attachment.

\section{INTRODUCTION}

Passenger-carrying equipment operating on the general railroad system is subject to regulations promulgated by FRA.
These regulations include structural strength and other crashworthiness requirements for the equipment [1]. These requirements are typically strength based; manual calculations can be performed to show compliance; and either implicitly or explicitly assume the presence of particular design features.

Equipment designed and built to foreign requirements is being considered for application in the US as new passenger rail systems and the expansion of existing systems are being planned. Application of FRA crashworthiness regulations to equipment designed to alternative standards may not be straightforward; such equipment may not have the specific design features assumed by the regulations.

Passenger rail equipment built to alternative designs may be considered for use on the US general rail system through a waiver request to the FRA. Due to the increasing interest in purchasing and operating passenger equipment designed and built to foreign standards, waiver requests have been on the rise.

In consultation with the rail industry, FRA is developing alternative criteria and procedures for assessing the crashworthiness of rail passenger equipment that are applicable to a wide range of equipment designs. These criteria and procedures are intended to be used by the rail industry in developing information to support waiver petitions and by the FRA in evaluating waiver petitions. They are being developed to encourage the application of the latest crashworthiness technology, such as Crash Energy Management [2], and to facilitate the application of sophisticated evaluation procedures, such as computer simulations and destructive tests of components.

\section{Engineering Task Force}

In June 2009, at the request of the Federal Railroad Administration (FRA), the Railroad Safety Advisory 
Committee established the Engineering Task Force (ETF). The ETF is comprised of government, APTA members, labor unions and other railroad stakeholders.

The mission of the Task Force was to produce a set of technical criteria and procedures for evaluating passenger rail equipment built to alternative designs. The technical evaluation criteria and procedures would provide a means of establishing whether equipment of an alternative design would result in at least equivalent performance to that of equipment designed in accordance with the structural standards in the Passenger Equipment Safety Standards (49 CFR Part 238) [1]. The initial focus of this effort was on Tier I crashworthiness and occupant protection standards.

The criteria and procedures contained within the report [3] provide a technical framework for presenting evidence to FRA in support of a request for waiver of the Tier I crashworthiness and occupant protection standards, including the compressive (buff) strength requirements set forth in 49 CFR $\S 238.203$. The criteria and procedures form a technical basis for making determinations concerning alternative compliance with the Tier I crashworthiness and occupant protection standards, other than $\S$ 238.203. See § 238.201(b).

This paper describes the collision scenario-based safety requirements. The train-level requirements are based on a train-to-train collision scenario. In the prescribed scenario, the space for the crew and passengers must be preserved, colliding equipment must not override, coupled equipment must not override, and the trucks must remain attached. These requirements are significantly different from the existing Tier I regulations, which have no specific train-level or scenariobased requirements for crashworthiness.

In this paper, the following four topics are covered:

1) Collision with Conventional Equipment

2) Colliding Equipment Override

3) Connected Equipment Override

4) Truck Attachment

For each of these topics, the concern, criteria, procedures and key results are described. The described procedures are examples of how to apply the criteria. The purpose of these examples is to show that the criteria are practical, and can be applied using modern engineering techniques.

A companion paper describes the issues, criteria and procedures pertaining to demonstrating compliance with carlevel requirements, specifically occupied volume strength [4].

\section{REQUIREMENT: COLLISION WITH CONVENTIONAL EQUIPMENT \\ Concern}

Preserving occupied volume is accomplished primarily with strength of the structure. If the occupant compartment is sufficiently strong, there will be sufficient, survivable space for the occupants. Secondary impacts are limited through a combination of structural crashworthiness and occupant protection measures. Allowing portions of the vehicle to crush in a predetermined manner can limit the forces applied to the structure surrounding the occupied volume and control the decelerations of the cars. Conventional practice is oriented toward making the individual cars uniformly strong, and principally attempts to control the behavior of individual cars during a collision. As shown through full-scale testing [1] (see Figure 1) and confirmed through review of accident history, the lead car in a train-to-train collision may be overwhelmed. The CEM approach is train-oriented, controlling the load into the occupied volume and apportioning the structural crushing to unoccupied areas throughout the train. To measure the crashworthiness of a CEM trainset, a collision scenario-based evaluation is appropriate.

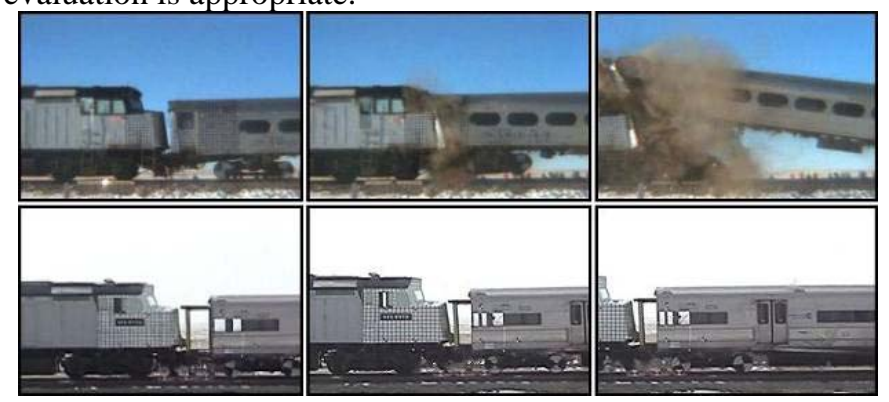

Figure 1. Frames from High-speed Movies of Conventional (top) and CEM (bottom) Train-to-Train Tests

\section{Criteria}

While there is no analog to this collision scenario presently included in the CFR for Tier I passenger equipment, the combination of a dynamic collision evaluation and a quasistatic occupied volume integrity evaluation [4] helps provide assurance of sufficient resistance to loss of occupied volume. If the proposed equipment is demonstrated to meet the scenario-based criteria described below, a waiver of the requirements of §238.203 may be justified.

The evaluation collision scenario is defined as follows:

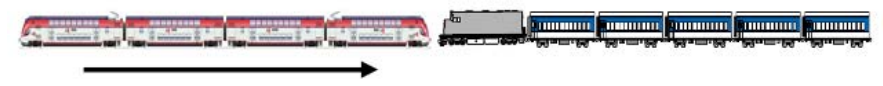

Figure 2. Collision Scenario - Collision with Conventional Train Equipment

- Initially Moving Train: The train is made up of alternatively-designed equipment at AW0 ready-to-run condition. The length of the consist reflects its planned operational use. If train configurations of varying consist length are intended for use, the configuration having the longest consist length shall be evaluated. If the train is intended for push-pull service, then both the cab car-led and conventional locomotive-led configurations shall be evaluated separately.

- Initially Standing Train: This train is a conventional locomotive-led passenger train. The train consists of one leading, conventional locomotive weighing 260,000 lbs and five conventional passenger cars each weighing 95,000 lbs. 
$\underline{\text { Initial Conditions }}$

- Tangent, Level Track.

- Moving Train Impact Speed:

o A) $20 \mathrm{mph}$, if cab car- or MU locomotive-led train, or

o B) $25 \mathrm{mph}$, if conventional locomotive-led train

- Coupler knuckles are closed for each colliding vehicle.

- Moving and standing train are not braked.

- The standing train has only one degree of freedom (longitudinal direction).

$\underline{\text { Results }}$

- $\quad$ Preserve interior spaces occupied by passengers.

- The occupied volume for the passengers shall have no more than 10 inches of longitudinal, permanent deformation; or

- Global vehicle shortening shall be no more than $1 \%$ over any $15 \mathrm{ft}$ of the occupied volume.

- $\quad$ Maintain safe secondary impact environment.

- Compare the secondary impact velocity (SIV) curve, calculated at the center of gravity (CG) of each car/locomotive, to the SIV curve associated with the 8g, 250-millisecond triangular crash pulse.

- $\quad$ Preserve interior space for engineer.

- $\quad$ Each seat in the operating compartment shall have a survival space where there is no intrusion after the collision scenario;

- $\quad$ The survival space shall extend a minimum of 12inches from the edge of the seat;

- $\quad$ Flip down seats will not be utilized;

- $\quad$ There shall be a clear exit path for the occupants after the collision scenario;

- $\quad$ The vertical height of the compartment (floor to ceiling) shall not be reduced by more than $20 \%$ after the collision scenarios, and;

- $\quad$ The operating console shall not move closer to the engineer's seat after the collision scenario.

Figure 3 shows an overhead view of the engineer's seat. The 12-inch-wide minimum survival space on each side of the seat is indicated in this figure. No intrusion is permitted to occur within the boundaries of the dashed line during the collision scenario.

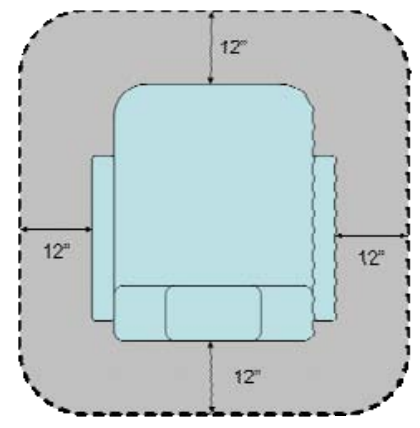

Figure 3. Engineer's Seat with Survival Space Indicated

\section{Example Procedures}

A collision dynamics analysis is used to demonstrate compliance with the scenario requirements. The following sections highlight two analysis types used for determining train-level crashworthiness performance: a lumped-parameter evaluation and a finite element evaluation.

Figure 4 shows the procedure for conducting a collision dynamics evaluation.

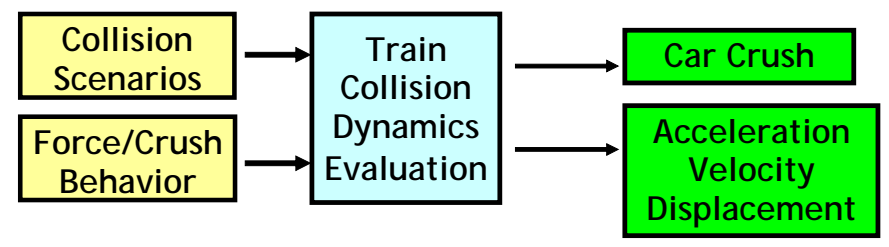

Figure 4. Key Inputs and Outputs for Collision Dynamics Evaluation

Entities submitting waiver requests may select any engineering-based procedure that they find appropriate. An overview of the procedure used by the submitting entity should be included in the waiver request. The purpose of the following examples is to show that the established criteria are practical, and can be applied using modern engineering techniques.

\section{Lumped-Parameter Evaluation}

Figure 5 is a schematic of a lumped-mass model for the given collision scenario of a cab-car led consist. The moving consist should include the appropriate number and configuration of vehicles for the equipment being evaluated. For example, an MU train could be made up of 4 MUs with the appropriate masses to reflect the train make-up proposed for operation. In the lumped-mass analyses, motion is constrained to longitudinal translation only. Each vehicle may be considered a single, rigid mass and car ends are characterized by deformable springs with prescribed force-deflection characteristics.

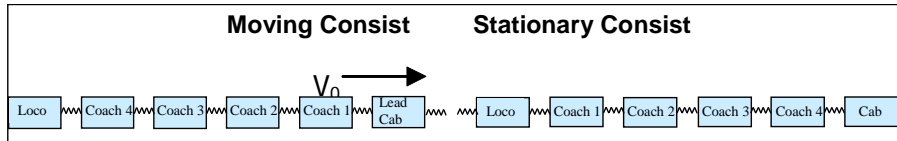

Figure 5. Schematic of a Lumped-parameter Model for a Trainto-train Collision Scenario 
Table 1 shows key input parameters for example equipment train designs. Each vehicle end must preserve occupied space in accordance with the criteria for the collision scenario. The point of intrusion for each vehicle end depends on the specific seating configuration and layout of occupied space.

Table 1. Key Inputs for Lumped-Parameter Model

\begin{tabular}{|c|c|c||c|}
\hline Equipment & $\begin{array}{c}\text { Example A: } \\
\text { FRA-Prototype CEM Train }\end{array}$ & $\begin{array}{c}\text { Example B: } \\
\text { Proposed Alternate } \\
\text { Train }\end{array}$ & $\begin{array}{c}\text { Scenario 1: } \\
\text { Conventional } \\
\text { Standing Train }\end{array}$ \\
\hline $\begin{array}{c}\text { Train Make- } \\
\text { up }\end{array}$ & $\begin{array}{c}\text { Cab car, 4 coach cars and } \\
\text { conventional locomotive }\end{array}$ & $4 \mathrm{MU}$ consist & $\begin{array}{c}\text { Conventional } \\
\text { locomotive, } 4 \text { coach } \\
\text { cars, cab car }\end{array}$ \\
\hline Speed & $20 \mathrm{mph}$ & $20 \mathrm{mph}$ & Stationary \\
\hline $\begin{array}{c}\text { Vehicle } \\
\text { Weights }\end{array}$ & $\begin{array}{c}\text { Cab car= } 95 \mathrm{kips} \\
\text { Coch }=95 \mathrm{kips}\end{array}$ & $\mathrm{MU}=95 \mathrm{kips}$ & $\begin{array}{c}\text { Locomotive }=260 \\
\text { kips }\end{array}$ \\
\hline \hline $\begin{array}{c}\text { Level of } \\
\text { Braking }\end{array}$ & None kips & & $\begin{array}{c}\text { kips } \\
\text { None }\end{array}$ \\
\hline
\end{tabular}

Figure 6 illustrates another key input to the lumpedparameter collision dynamics model, the idealized force-crush characteristics for different types of equipment. The graph illustrates the force-crush characteristics for the FRA-prototype CEM equipment (both cab end and non-cab end) and the second graph illustrates force-crush characteristics for example alternatively-designed equipment. The dashed line at the righthand-end of each characteristic represents the behavior of the occupied volume of each vehicle end once its CEM features have been exhausted and its occupied volume integrity compromised.

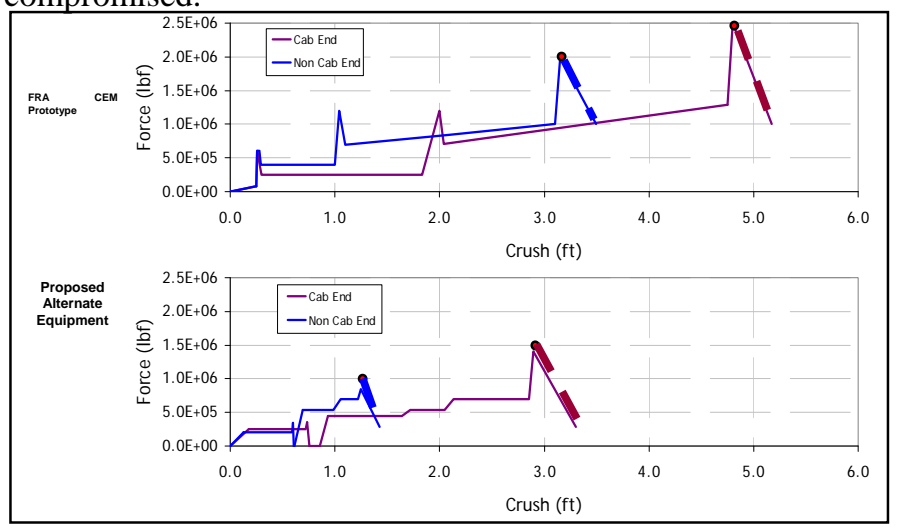

Figure 6. Example Idealized Force-crush Characteristics

Two key results are required to describe the crashworthiness performance of alternatively-designed equipment for the collision scenario:

1) Crush results to demonstrate that occupied volume crush meets the criteria; and
2) Gross motions of each car in the consist to estimate the secondary impact environment.

The flowchart in Figure 7 shows a procedure for postprocessing collision dynamics model results to evaluate occupied volume crush. The cab layout on cab ends and seating layout at each car end determine the points at which occupied space is compromised. The total loss of occupied volume in a given analysis must be compared with the values established in the Criteria section to determine if the scenario meets the crashworthiness and occupant protection performance criteria.

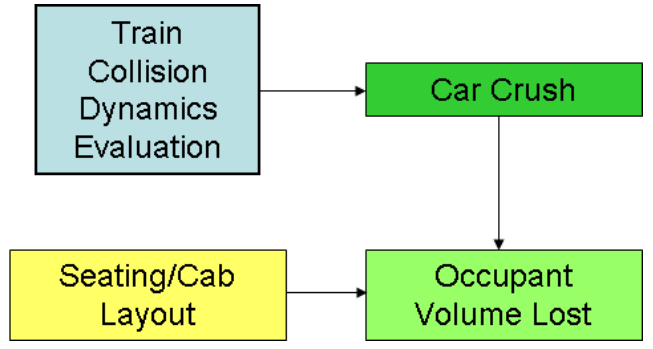

Figure 7. Flowchart Showing Procedure for Calculating Intrusion into Occupied Volume

Figure 8 shows example results from a collision dynamics analysis. The bar chart shows crush at each coupled connection in the initially-moving consist. The total crush plotted at each connection is the sum of the crush at each of the two connected ends. The points on the corresponding forcecrush characteristics indicate the amount of car crush at each car end. These results demonstrate that occupied volume is preserved throughout the train, as the peak load is not exceeded at any car end.

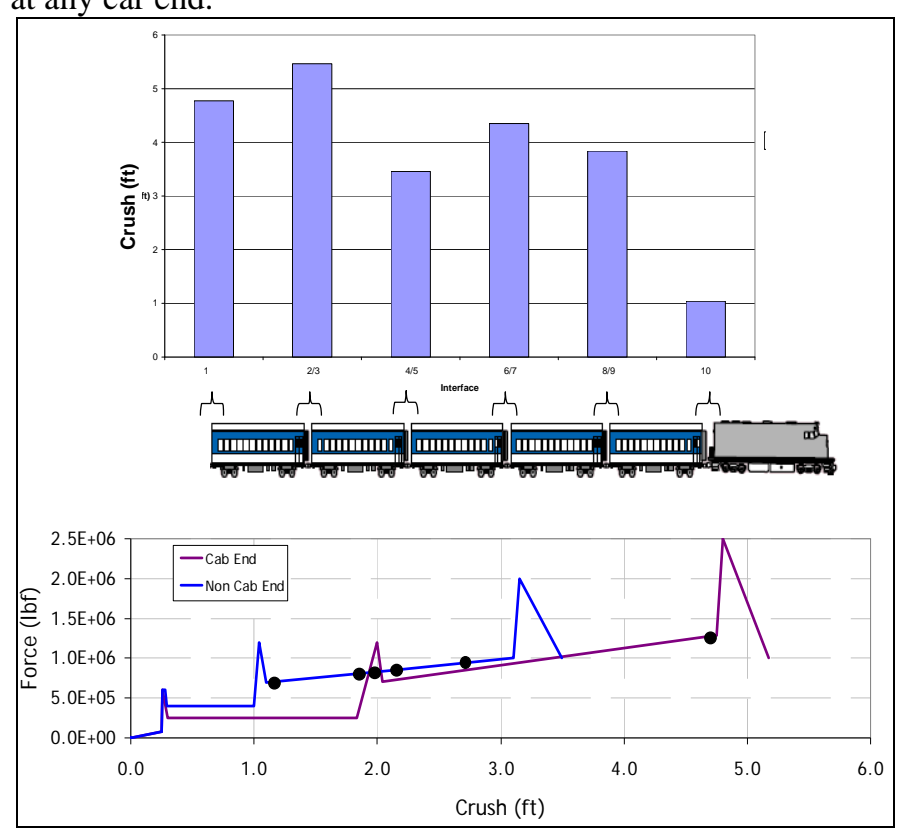

Figure 8. Example Crush Results from a One-Dimensional Lumped-Mass Model: Crush Distribution for Each Car End in the Consist 
The flowchart in Figure 9 shows a procedure for postprocessing collision dynamics model results to estimate the secondary impact environment. Output from the collision dynamics analysis includes the acceleration, velocity, and displacement history of each vehicle.

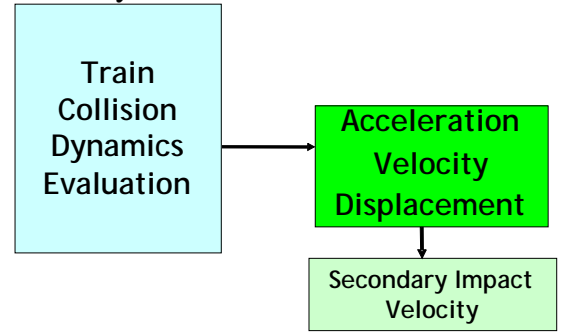

Figure 9. Flowchart Showing Procedure for Calculating SIV Estimates

Following this paragraph are results from a train-to-train collision dynamics analysis. These results are shown as an example of the procedures for calculating the secondary impact velocities and do not reflect results for the specific collision conditions described in the criteria document.

Figure 10 shows the relative displacement-time data and the relative velocity-time data at the center of gravity (CG) of each car in the moving consist. The relative displacement ( $\mathrm{x}$ axis) and velocity (y-axis) data are plotted against one another to develop the SIV characteristics for each car.

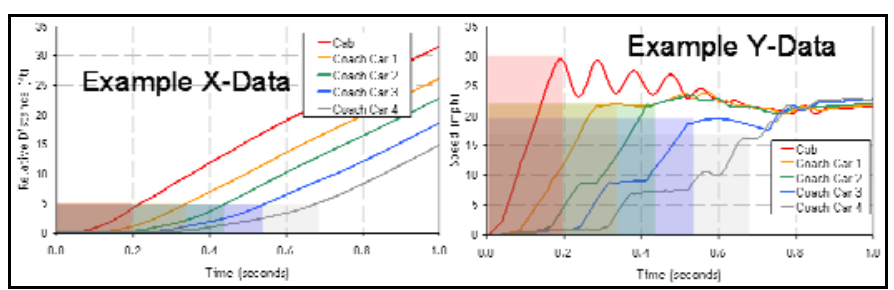

Figure 10. Relative Displacement and Relative Velocity Plots for Moving Consist

The SIV characteristics for all of the cars in the moving consist are plotted in Figure 11. From this plot, the SIVs can be estimated for allowable travel distance in specific seating configurations for each car. These results give an estimate of the severity of the collision environment for this equipment with the particular seating configurations planned for use.

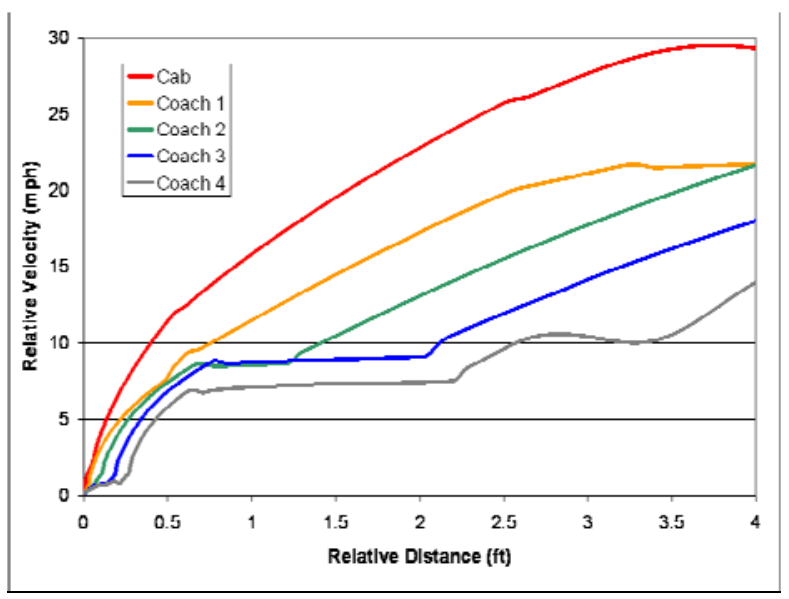

Figure 11. Example SIV Characteristics

\section{Finite Element Evaluation}

A finite element analysis may also be used to demonstrate compliance with the scenario requirements. In the following example the inputs required for the finite element analysis and shown in Figure 4 are described as well as a description of example results.

Figure 12 is a schematic of a finite element model for the given collision scenario. In this evaluation, the collision scenario is simulated using three-dimensional finite element analysis at the collision interface with one-dimensional lumped-mass simplification of all trailing cars. The moving consist should include the appropriate number and configuration of vehicles for the equipment being evaluated. The model includes a full three-dimensional representation of the first vehicle in each consist in order to properly capture the deformation of each vehicle end involved at the collision interface. The trailing vehicles in each consist are modeled using one-dimensional lumped-mass analyses, where motion is constrained to longitudinal translation only. Each trailing vehicle may be considered a single, rigid mass and car ends are characterized by deformable springs with prescribed forcedeflection characteristics. Each trailing vehicle is assigned the appropriate mass, similar to the parameters shown in Table 1.

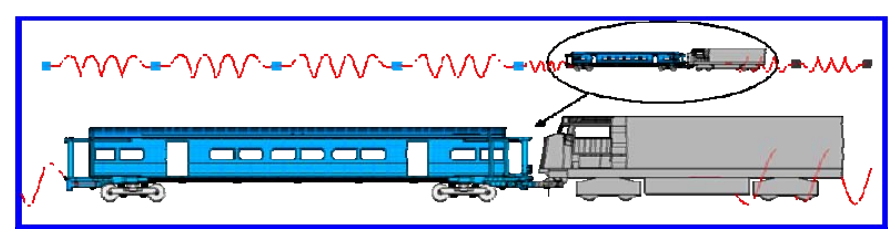

Figure 12. Schematic of a Finite Element Model for a Train-totrain Collision Scenario

Figure 13 illustrates another key input to the finite element model, the idealized force-crush characteristics for different types of equipment. The top schematic illustrates force-crush characteristics for passenger equipment and the bottom schematic illustrates force-crush characteristics for freight equipment. 


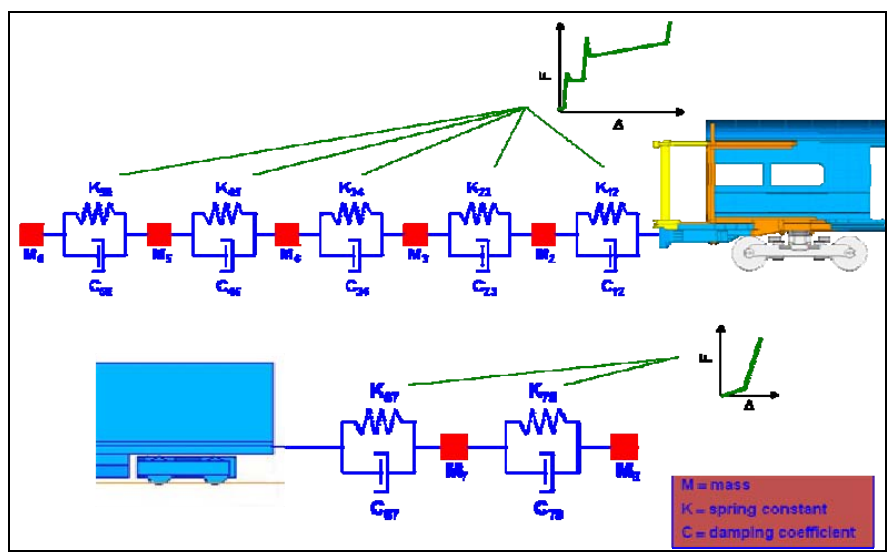

Figure 13. Example Idealized Force-crush Characteristics

As with the lumped-parameter analysis results, two key results are required to describe the crashworthiness performance of alternatively-designed equipment for the collision scenario:

1) Crush results to demonstrate that occupied volume crush meets the criteria; and

2) Gross motions of each car in the consist to estimate the secondary impact environment.

The flowchart in Figure 7 shows a procedure for postprocessing finite element model results to evaluate occupied volume crush. The cab layout on cab ends and seating layout at each car end determine the points at which occupied space is compromised. The total loss of occupied volume in a given analysis must be compared with the values defined in the Criteria section to determine if the scenario meets the crashworthiness and occupant protection performance criteria.

Figure 14 shows example results from a finite element analysis. The figure shows the crush at the collision interface. In this analysis there was no intrusion into the engineer's compartment and there was no plastic deformation of the passenger compartment. Figure 15 is an example of the collision force-crush curve, calculated from the train motions. The figure shows that the calculated force is consistent with the design target. The result must demonstrate that occupied volume is preserved throughout the train, and the peak load is not exceeded at any car end.

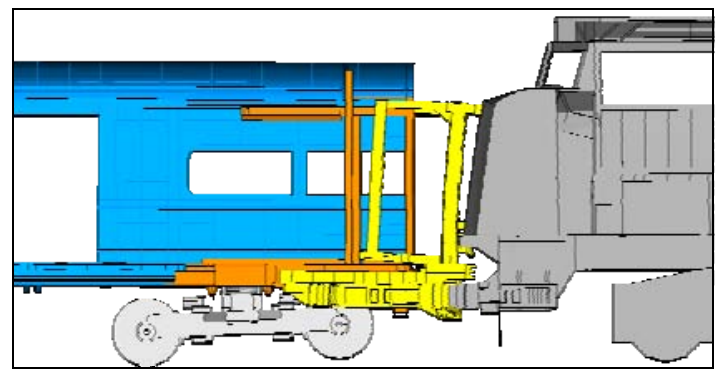

Figure 14. Example Crush Results from Finite Element Analysis: Crush at Collision Interface

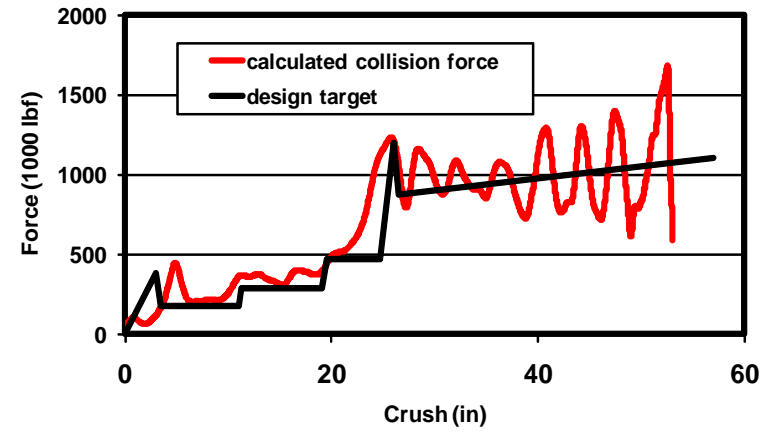

Figure 15. Example Force-Crush Results from Finite Element Analysis

The flowchart in Figure 9 shows a procedure for postprocessing finite element model results to estimate the secondary impact environment. Output from the finite element analysis includes the acceleration, velocity, and displacement history of each vehicle.

Example velocities for all of the cars in the moving consist are plotted in Figure 16. From this data, the SIVs can be estimated for allowable travel distance in specific seating configurations for each car. These results give an estimate of the severity of the collision environment for this equipment with the particular seating configurations planned for use.

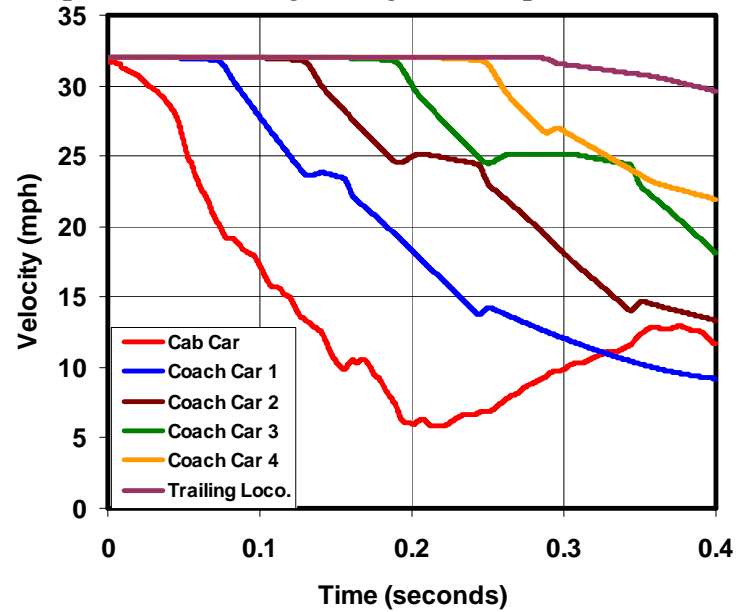

Figure 16. Example Velocities of Vehicles in the Moving Consist

\section{REQUIREMENT: COLLIDING EQUIPMENT OVERRIDE Concern}

Figure 17 shows the interaction of colliding equipment for both a train-to-train test [5] and an actual train-to-train collision in Beverly, MA [6]. In both cases, the colliding cab car overrode the colliding conventional locomotive. The deformation mode observed in the test involved the end frame of the cab car engaging the short hood of the conventional locomotive. Deformation of the cab car structure behind the end frame led to the override. In essence, the underframe structure deformed into a ramp, allowing the cab car to override the conventional 
locomotive. Photographs from the Beverly, MA accident indicate that the same mechanism allowed override in the accident as in the test. In both the test and the accident, the anti-climbing features were effective; the failure occurred in the underframe structures.

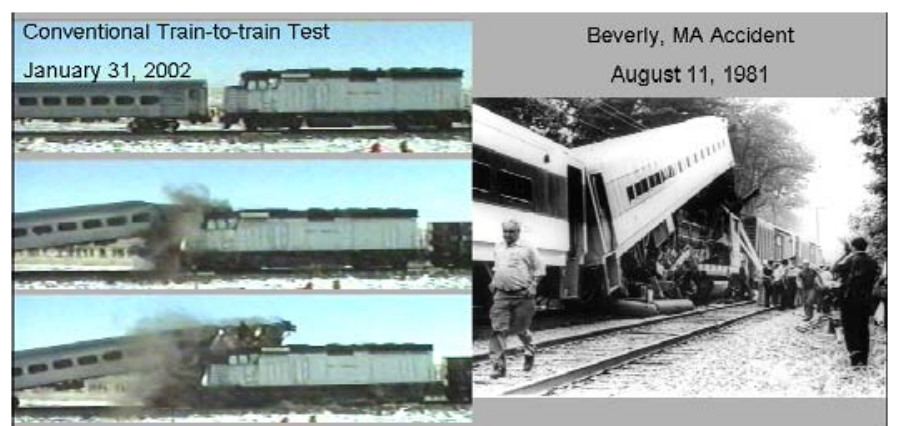

Figure 17. Cab Car Interaction with Conventional Locomotive in a Collision

The colliding and connected car override criteria prescribe the kinematic behavior of the equipment for ideal and offset conditions. The ideal condition is the equipment positioned at its design height and centered on the track. The offsets for colliding equipment -3 inches vertically and 3 inches laterally - are based on the offsets used by Metrolink in procuring their equipment with CEM features [7]. The offset conditions are intended to help assure that design of override features is robust.

\section{Criteria}

Title 49 CFR Requirement, $\S$ 238.205. Anti-climbing mechanism.

\section{Option}

Given the scenario described the Collision with Conventional Equipment section, anti-climb features shall be demonstrated for each of the following sets of initial conditions:

1) All cars in the moving and standing consists are positioned at their nominal running heights.

2) The moving consist is positioned at its nominal running height and the standing consist is positioned 3 inches below its nominal running height and offset 3 inches laterally from its nominal centerline.

The pass/fail criteria are as follows:

- The relative difference in elevation of the underframes of the colliding and connected equipment shall not change by more than 4 inches; and

- The treads of all wheels of the alternatively-designed equipment shall not rise above the top of rail more than 4 inches.

\section{Example Procedure}

The following example procedure illustrates the crush analyses performed on the FRA-prototype CEM equipment to demonstrate that the anti-climb features will limit the potential for override in a train-to-train collision scenario. Two different collision scenarios are analyzed: one impact under ideal conditions and a second impact under offset conditions. Figure 18 shows the initial conditions for an offset analysis with the conventional locomotive lowered and moved laterally by a prescribed amount. This analysis was run in preparation for a test, and the offset values are greater than in the above stated criteria. However, the same analysis techniques used to prepare for the test may be used to show that the criteria are met.
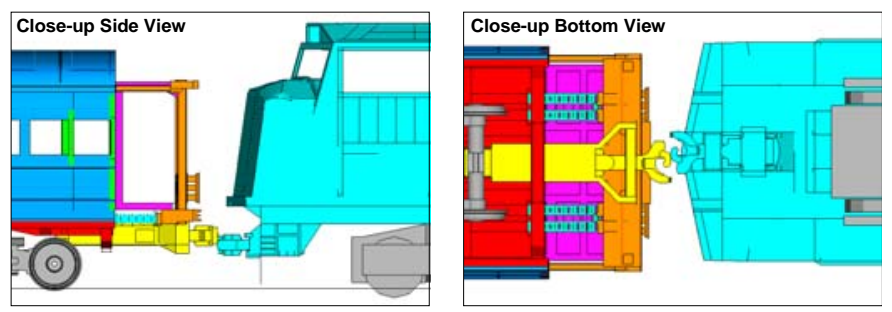

Figure 18. Dynamic Crush Analysis with Lateral and Vertical Offsets

Note that while only the impacting interface is shown in this figure, compliance with the criteria requires analysis of the alternatively-designed equipment in the configuration it is intended to be used. If the alternatively-designed equipment will be used in multiple configurations (e.g., a single four-car trainset, or two four-car trainsets coupled together) analysis of each such configuration is required.

Figure 19 and Figure 20 show the deformation of the cab car from the analysis under ideal conditions and from the offset case, respectively. In both cases, the cab car lifted less than one inch and the vertical displacement of the conventional locomotive was negligible. In neither case were any of the trucks unloaded, nor did wheel lift occur. Consequently, these analyses demonstrate the requirements of the criteria are met.

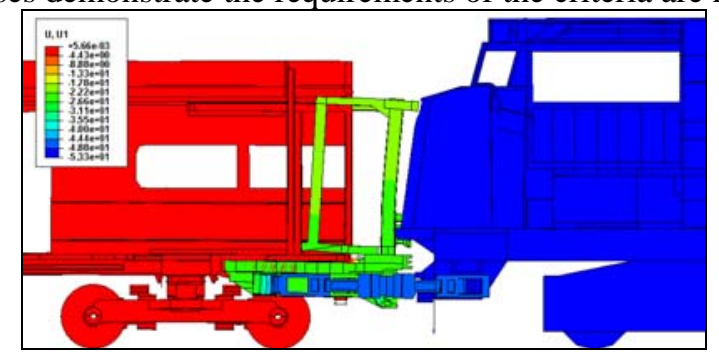

Figure 19. Displacement Results from Dynamic Crush Analysis: Ideal Impact Conditions

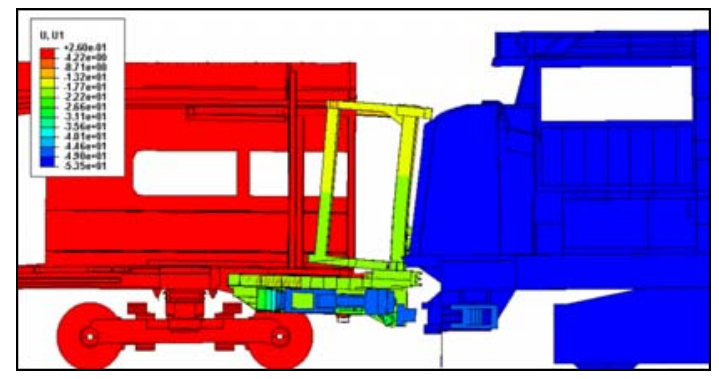

Figure 20. Displacement Results from Dynamic Crush Analysis: Offset Impact Conditions 


\section{REQUIREMENT: OVERRIDE \\ Concern \\ CONNECTED}

Figure 14 shows the interaction of connected equipment during a full-scale test and collision condition. During such collision conditions both vertical and lateral offsets may occur which can aggravate the potential for override.

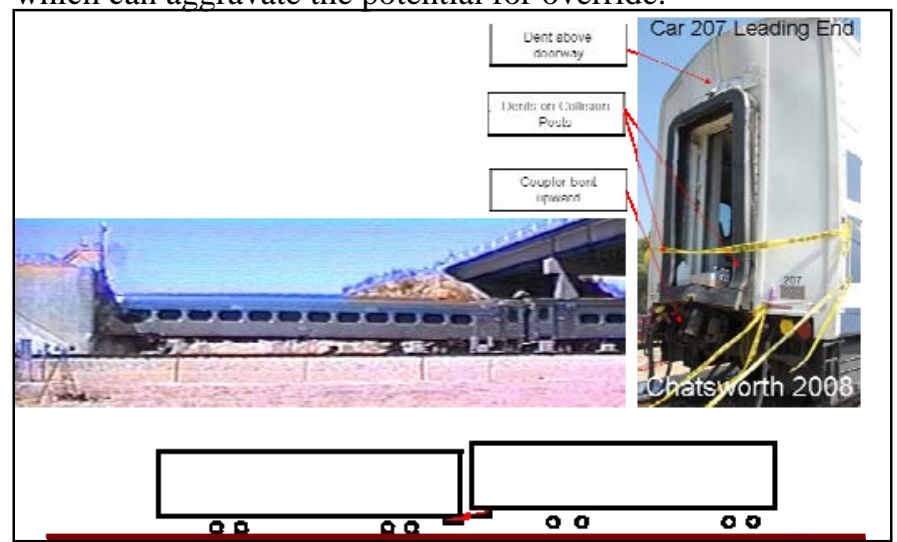

Figure 21. Non-CEM Connected Equipment Interaction in a Collision

The lateral offset for connected equipment is based on the conventional and CEM two-car impact tests [8,9]. The location of the prescribed connected car offsets is at the first connected interface in the train. These offsets have different influences on coupled equipment than on articulated equipment.

\section{Criteria}

Title 49 CFR Requirement, § 238.205. Anti-climbing mechanism and $\S 238.207$. Link between coupling mechanism and car body.

\section{Option}

For passenger equipment that is connected by pushback couplers and incorporates anti-climbing features that comply with the requirements of $\S 238.205(a)$, such passenger equipment provides minimally-acceptable anti-climbing performance. Given the scenario described by the text accompanying Figure 2, anti-climb features shall be demonstrated for each of the following sets of initial conditions:

1) All cars in the moving and standing consists are positioned at their nominal running heights.

2) The first car-to-car interface of the initially-moving consist is perturbed laterally and vertically by 2 inches, the remainder of the moving consist is positioned at its nominal running position, and the standing consist is positioned at its nominal running position.

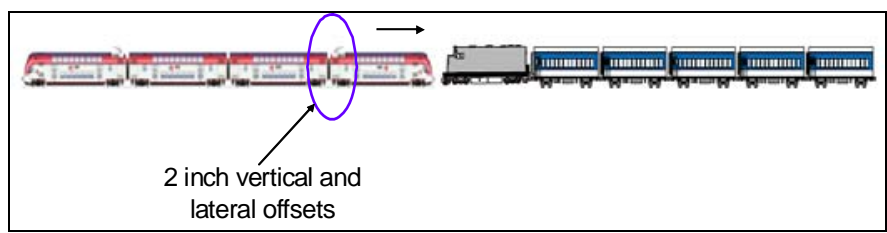

Figure 22. Location of Offsets in Moving Consist

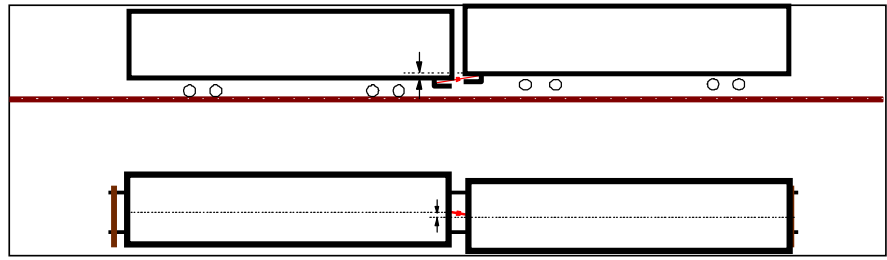

Figure 23. Illustration of Offsets for Coupled Cars

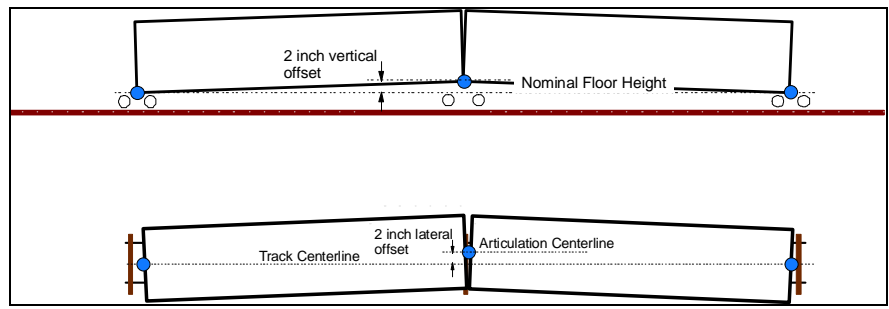

Figure 24. Illustration of Offsets for Articulated Cars

The pass/fail criteria are as follows:

- The relative difference in elevation of the underframes of the connected equipment shall not change by more than 4 inches; and

- The treads of all wheels of the alternatively-designed equipment shall not rise above the top of rail more than 4 inches.

\section{Example Procedure}

This section includes example procedures for evaluating connected equipment override. The procedures and results in this section show the types of analyses and results that demonstrate compliance with the criteria. Other procedures may be used in evaluating a particular design.

Using a finite element model that included the first two cars of the passenger train and the rigid geometry of the standing locomotive, a dynamic crush analyses was conducted to evaluate ideal impact conditions. The same model can be used with different initial conditions for the offset impact condition. Figure 25 shows the model used for this example analysis. This analysis was performed by Alstom, on a multilevel, multiple-unit trainset. 


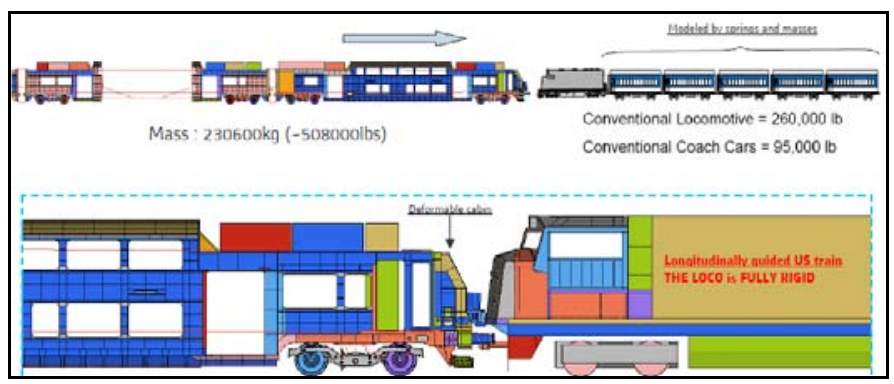

Figure 25. Dynamic Crush Analysis: Ideal Impact Conditions (Courtesy Alstom)

Figure 26 is a graphic from the analysis at the time of maximum vertical displacement between the two cars at the first coupled interface. There are various labels on the figure indicating points that were tracked for vertical displacement. Also, in the lower-right portion of the figure there is a red oval around the gooseneck area of the underframe. There was a modest amount of permanent deformation at this location, which was the principal source of the vertical motion.

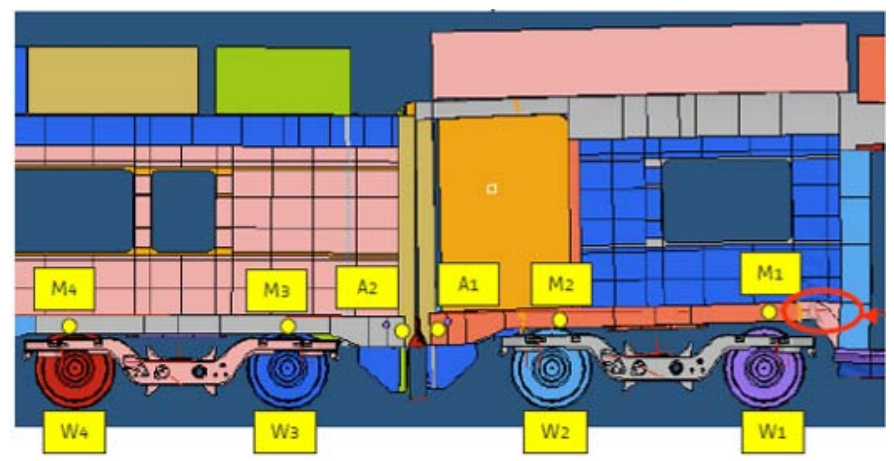

Figure 26. Deformation in Coupled Car Dynamic Crush Analysis: Ideal Impact Conditions (Courtesy Alstom)

Figure 27 shows the time history of the relative vertical displacement between the two coupled cars shown in Figure 26. The maximum relative displacement is 1.6 inches, which is less than the 4 inches allowed by the criteria.

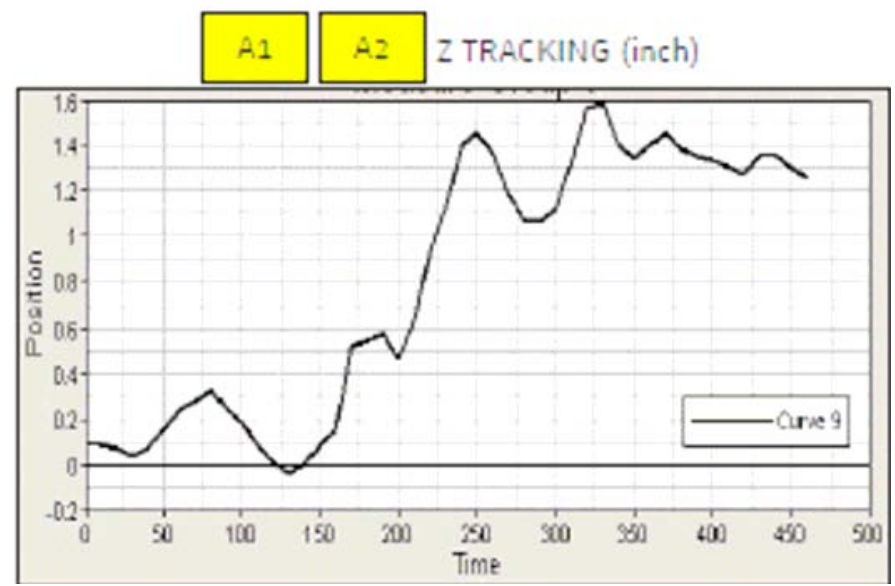

Figure 27. Relative Vertical Displacement of the Underframes of Two Coupled Cars (Courtesy Alstom)

Figure 28 shows the vertical displacement-time history of the wheels seen in Figure 26. As can be seen on the plot shown in the figure, the wheels remain on the track for the entire simulation. This demonstrates compliance with the criteria that no wheel lifts above the rail by 4 inches or more.

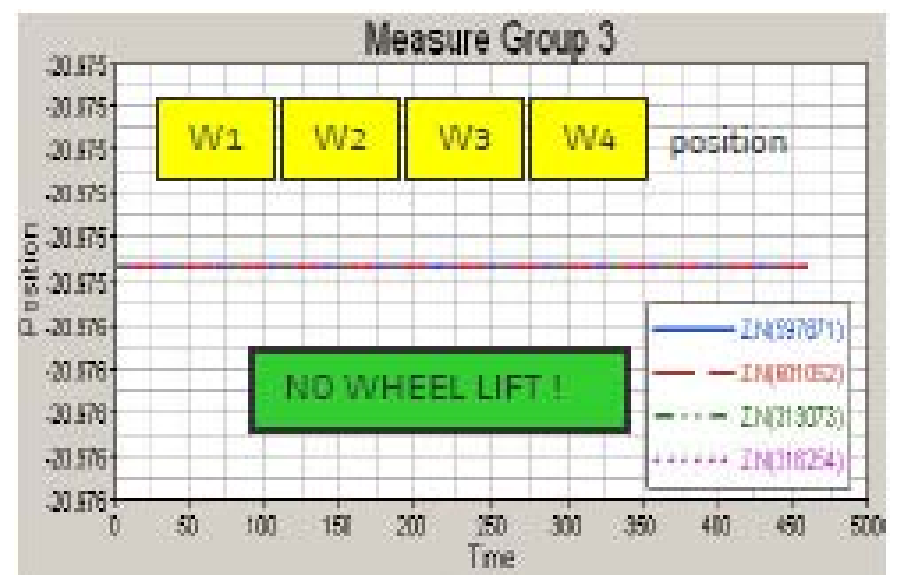

Figure 28. Vertical Displacement of Four Wheels (Courtesy Alstom)

\section{REQUIREMENT: TRUCK ATTACHMENT Concern}

Truck attachments compliant with Tier I requirements are effective in many accidents, but have not been effective in retaining the trucks in all circumstances. Figure 29 shows accidents and a full-scale test in which trucks have become detached. 

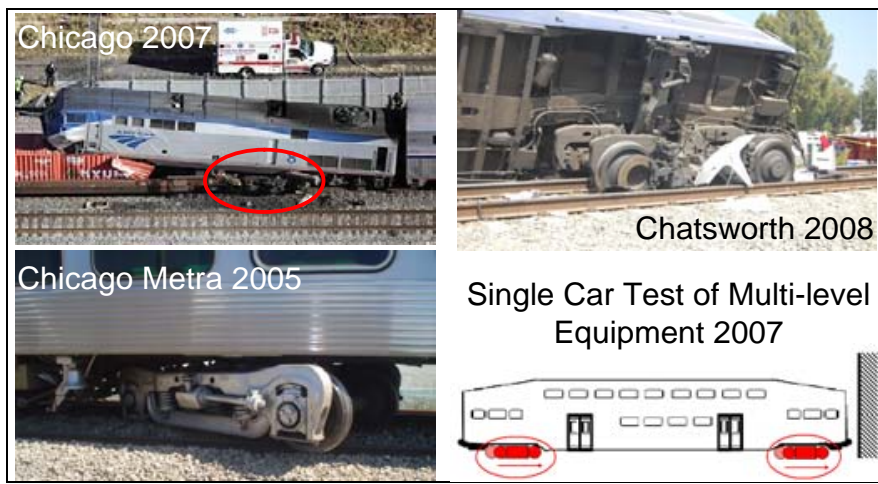

Single Car Test of Multi-level Equipment 2007

Figure 29. Accident Conditions in which Trucks Have Become Detached

\section{Criteria}

Title 49 CFR Requirement, § 238.219. Truck-to-car-body attachment.

The following options are provided as alternatives to the regulation in order to demonstrate sufficient truck-to-car-body attachment. The equipment must comply with either the regulation, or at least one of these alternatives to demonstrate compliance with the criteria stated.

\section{Option A}

Passenger equipment shall have a truck-to-car-body attachment with strength sufficient to resist without yield the following individually-applied quasi-static loads on the mass of the truck at its center of gravity: $3 \mathrm{~g}$ vertically; $5 \mathrm{~g}$ longitudinally, along with the resulting vertical reaction to this load; and $1 \mathrm{~g}$ laterally, along with the resulting vertical reaction to this load. For the purposes of this option, the mass of the truck includes axles, wheels, bearings, the truck-mounted brake system, suspension system components, and any other component attached to the truck by design.

In addition, for the nominal initial conditions given in the collision scenario shown in Figure 2 and described in that section:

- The average longitudinal deceleration of the car during the impact shall not exceed 5g; and

- The peak longitudinal deceleration of the truck shall not exceed $10 \mathrm{~g}$.

\section{Option B}

Passenger equipment shall have a truck-to-car-body attachment with strength sufficient to resist without yield the following individually-applied quasi-static loads on the mass of the truck, at its center of gravity: $3 g$ vertically and $1 \mathrm{~g}$ laterally, along with the resulting vertical reaction to these loads. For the purposes of this option, the mass of the truck includes axles, wheels, bearings, the truck-mounted brake system, suspension system components, and any other component attached to the truck by design.

In addition, the truck shall remain attached during the scenario shown in Figure 2 and described in that section.

\section{Example Procedures}

The procedures and results in this section show the types of analyses and results that demonstrate compliance with the criteria for truck attachment strength. Other procedures may be followed in demonstrating compliance.

The truck attachment was evaluated using Option A in this example. This evaluation was conducted using the results of a single simulation. This simulation was performed for ideal, inline initial conditions. The model was developed and analysis performed by Alstom, (refer to schematic in Figure 25).

Figure 30 shows the deceleration-time history of the cab car described in Section 4.8 and Figure 31 shows the deceleration-time history of the lead truck of that cab car. As shown in Figure 30, the average deceleration of the cab car was just over $4 \mathrm{~g}$, which is less than the $5 \mathrm{~g}$ permitted by the Criteria. The average deceleration was calculated from initial contact between the cab car and locomotive until the contact force dropped to zero. The peak deceleration of the cab car is $15 \mathrm{~g}$, which is nearly four times the average deceleration. The cab car deceleration time-history shown in Figure 30 is a direct output from the simulation. As shown in Figure 31, the maximum deceleration of the truck is $10 \mathrm{~g}$, which is the maximum permitted by the Criteria. The truck deceleration time-history is also a direct output from the simulation, and has been filtered with a zero-phase fourth-order Butterworth filter meeting the SAE CFC 100 specification. The simulation results indicate both of the criteria are met.

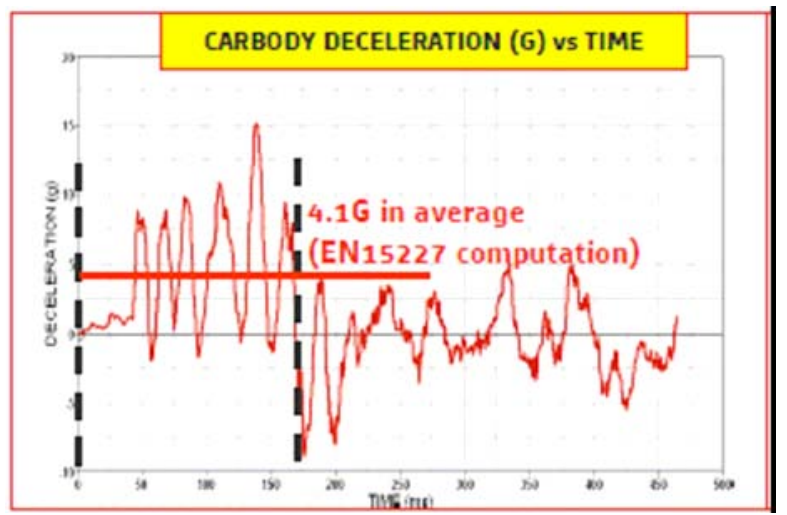

Figure 30. Cab Car Deceleration-time History (Courtesy Alstom)

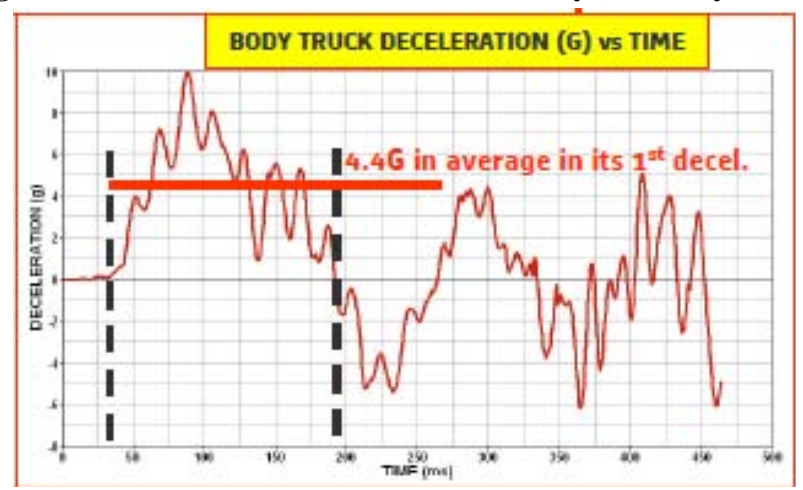

Figure 31. Cab Car Lead Truck Deceleration-time History (Courtesy Alstom) 


\section{SUMMARY}

The ETF is a government/industry working group, organized under the auspices of the Railroad Safety Advisory Committee (RSAC). The mission of the Engineering Task Force was to produce a set of technical criteria and procedures for evaluating passenger rail equipment built to alternative designs. The technical evaluation criteria and procedures would provide a means of establishing whether equipment of an alternative design would result in at least equivalent performance to that of equipment designed in accordance with the structural standards in the Passenger Equipment Safety Standards (49 CFR Part 238). The initial focus of this effort was on Tier I crashworthiness and occupant protection standards. This report is the product of this effort.

The Criteria and Procedures document outlines minimum information needed for the FRA to make an assessment of the alternatively designed passenger rail equipment. These criteria and procedures take advantage of the latest technology in rail equipment crashworthiness. The criteria and procedures include aspects which are fundamentally different from current regulations, such as the scenario-based train-level requirements and options for demonstrating occupant volume integrity. No such requirements exist in FRA's current Tier I regulations. Numerical values of the pass/fail criteria have been selected to provide an equivalent level of crashworthiness as the current Tier I regulations.

The criteria and procedures contained within the final document provide a technical framework for presenting evidence to FRA in support of a request for waiver of the Tier I crashworthiness and occupant protection standards. (See, Rules of Practice (49 CFR Part 211) for rules on waiver petitions.) Additionally, the criteria and procedures form a technical basis for making determinations concerning alternative compliance with the Tier I crashworthiness and occupant protection standards, other than $\S 238.203$. These Criteria and Procedures are independent of the design features of the equipment, and consequently facilitate the application of the latest in passenger rail equipment crashworthiness and occupant protection technology.

\section{ACKNOWLEDGEMENTS}

The Volpe Center's contribution to ETF was part of the Federal Railroad Administration's Equipment Safety Research Program under the Office of Research and Development. The ETF was led by the Office of Safety of the Federal Railroad Administration. Volpe participated in the ETF group as technical advisors and coordinated the development of drafting the ETF report. Some of the results contributed to the example procedures and key results were provided by industry participating in the ETF. At the time of this paper's publication, the ETF has not finalized its recommended Criteria and Procedures.

Jo Strang, FRA Associate Administrator of Railroad Safety, and Robert C. Lauby, FRA Deputy Associate
Administrator for Regulatory and Legislative Operations, led the Engineering Task Force. Cindy Gross, FRA Facilitator, and Larry Wolverton, FRA RSAC Administrative Officer, coordinated and managed the task force. Martin Schroeder of APTA coordinated the APTA effort. Dan Alpert, FRA Trial Attorney, provided review and counsel.

Dominique Le Corre, Alstom, conducted example finite element analyses and contributed example results to the ETF, some of which were incorporated in this paper.

The research described in this paper was performed as part of the Equipment Safety Research Program sponsored by the Office of Research and Development of FRA. Eloy Martinez, Program Manager, Office of Railroad Policy and Development, managed the research-related effort. Kevin Kesler, Chief, Equipment and Operating Practices Division, reviewed and supported the research effort. Grady Cothen, former Deputy Associate Administrator for Safety Standards and Program Development, established the ETF and has coordinated FRA's regulations development and the passenger rail equipment crashworthiness research since the inception of this research.

\section{REFERENCES}

1 Code of Federal Regulations, Title 49, Part 238, Subpart CSpecific Requirements for Tier I Passenger Equipment.

2 Tyrell, D., Jacobsen, K., Martinez, E., “A Train-to-train Impact Test of Crash Energy Management Passenger Rail Equipment: Structural Results,” American Society of Mechanical Engineers, Paper No., IMECE2006-13597, November 2006.

3 US Department of Transportation, Federal Railroad Administration, "Technical Criteria and Procedures for Evaluating the Crashworthiness and Occupant Protection Performance of Alternatively-Designed Passenger Rail Equipment for Use in Tier I Service,” DOT/FRA/ORD-xx/xx.

4 Carolan, M., Tyrell, D., "Criteria and Procedures for Assessing Occupied Volume Integrity," American Society of Mechanical Engineers, Paper No. RTDF2010-42022, October 2010.

5 Tyrell, D., "Passenger Rail Train-to-Train Impact Test Volume I: Overview and Selected Results," US Department of Transportation, DOT/FRA/ORD-03/17.I, July 2003.

6 National Transportation Safety Board, "Head On Collision of Boston \& Maine Corp Extra 1731 East \& MBTA Train No. 570 on former Boston \& Maine Corp. Tracks, Beverly, Massachusetts, August 11, 1981”, RAR-82-01, March 1982.

7 Tyrell, D., Martinez, E., Jacobsen, K., Parent, D., Severson, K., Priante, M., Perlman, A.B., "Overview of a Crash Energy Management Specification for Passenger Rail Equipment," 
American Society of Mechanical Engineers, Paper No. JRC2006-94044, April 2006.

8 Tyrell, D., Severson, K., Zolock, J., Perlman, A.B., "Passenger Rail Two-Car Impact Test Volume I: Overview and Selected Results," US Department of Transportation, DOT/FRA/ORD-01/22.I, January 2002.

9 Jacobsen, K., Tyrell, D., Perlman, A.B., "Impact Tests of Crash Energy Management Passenger Rail Cars: Analysis and Structural Measurements," American Society of Mechanical Engineers, Paper No. IMECE2004-61252, November 2004. 